\title{
RESEARCH PRIORITIES FOR OCCUPATIONAL RADIATION PROTECTION
}

\author{
February 1994
}

A Background Report Prepared By

THE SUBPANEL ON OCCUPATIONAL RADIATION PROTECTION RESEARCH

For the Science Panel

$$
\text { of the }
$$

Committee on Interagency Radiation Research and Policy Coordination 
The Oak Ridge Institute for Science and Education (ORISE) was established by the U.S. Department of Energy to undertake national and international programs in science and engineering education, training and management systems, energy and environment systems, and medical sciences. ORISE and its programs are operated by Oak Ridge Associated Universities (ORAU) through a management and operating contract with the U.S. Department of Energy. Established in 1946, ORAU is a consortium of 82 colleges and universities.

The Committee on Interagency Radiation Research and Policy Coordination (CIRRPC)* is chartered through the Federal Coordinating Council for Science, Engineering and Technology (FCCSET), Office of Science and Technology Policy, Executive Office of the President, Washington, DC 20506. The Energy/Environment Systems Division of Oak Ridge Associated Universities provides technical and administrative assistance to CIRRPC.

This report was prepared under Contract DE-AC05-760R00033 between the U.S. Department of Energy and Oak Ridge Associated Universities.

Printed in the United States of America. Copies available by referring to publication number ORAU 94/A:24 and writing:

National Technical Information Service

U.S. Department of Commerce

5285 Port Royal Road

Springfield, VA 22161

NTIS price codes: Printed copy, A:03; Microfiche copy, A:01.

\section{NOTICES}

The opinions herein do not necessarily reflect the opinions of the sponsoring institutions of Oak Ridge Associated Universities.

This report was prepared as an account of work sponsored by the United States Government. Neither the United States nor the U.S. Department of Energy, nor any of their employees, makes any warranty, expressed or implied, or assumes any legal liability or responsibility for the accuracy, completeness, or usefulness of any information, apparatus, product, or process disclosed, or represents that its use would not infringe on privately owned rights. Reference herein to any specific commercial product, process, or service by trade name, mark, manufacturer, or otherwise, does not necessarily constitute or imply its endorsement, recommendation, or favor by the U.S. Government or any agency thereof. The views and opinions of authors expressed herein do not necessarily state or reflect those of the U.S. Government or any agency thereof.

*Departments of Agriculture, Commerce, Defense, Energy, Health and Human Services, Housing and Urban Development, Interior, Justice, Labor, State, Transportation, and Veterans Affairs; Environmental Protection Agency; Federal Emergency Management Agency; National Aeronautics and Space Administration; National Science Foundation; Nuclear Regulatory Commission; and the Office of Management and Budget. 


\section{DISCLAIMER}

Portions of this document may be illegible in electronic image products. Images are produced from the best available original document. 


\title{
RESEARCH PRIORITIES FOR OCCUPATIONAL RADIATION PROTECTION
}

\author{
February 1994
}

A Background Report Prepared By

THE SUBPANEL ON OCCUPATIONAL RADIATION

PROTECTION RESEARCH

For the Science Panel

of the

Committee on Interagency Radiation Research

and Policy Coordination 


\section{PREFACE}

This background report was prepared for the Science Panel of the Committee on Interagency Radiation Research and Policy Coordination by the Subpanel on Occupational Radiation Protection Research to record the information exchange between the Subpanel, government agencies and non-government organizations on health physics research needs. The information exchange, beginning 1989, and 1990 became the basis for subsequent Subpanel activities, particularly in internal dosimetry.

We wish to thank those individuals and organizations that offered their experience and expertise to assist in this endeavor.

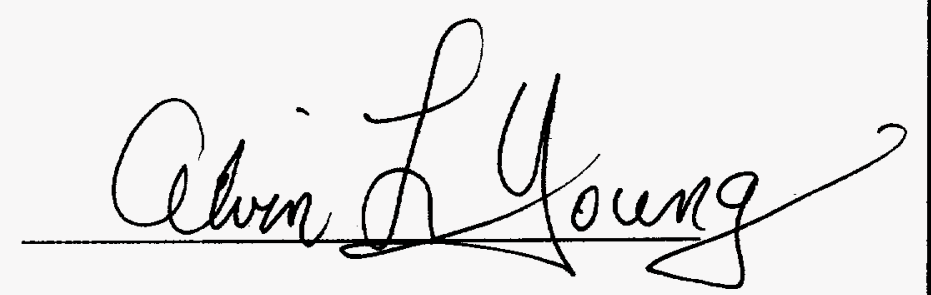

Alvin L. Young, Chairman

Committee on Interagency Radiation

Research and Policy Coordination

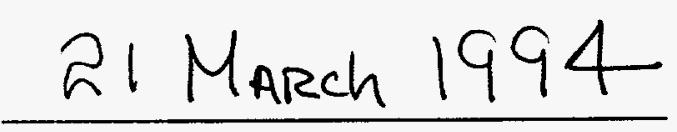

Date 
TABLE OF CONTENTS

Executive Summary $\ldots \ldots \ldots \ldots \ldots \ldots \ldots \ldots \ldots \ldots \ldots \ldots \ldots \ldots$

CHAPTER I

INTRODUCTION $\ldots \ldots \ldots \ldots \ldots \ldots \ldots \ldots \ldots \ldots \ldots \ldots \ldots$

Background

Work Statement

Objectives and Approach

Chapter II National OCcupational Radiation Protection

RESEARCH PRIORITIES $\ldots \ldots \ldots \ldots \ldots \ldots \ldots$ II-1

Overview

Basic Problem Areas that Require Nationally Focused Research

Assets and Mechanisms Needed to Enhance Research Efforts

CHAPTER III

CONCLUSIONS AND RECOMMENDATIONS WITH

PROJECTED MECHANISMS TO ADDRESS CRITICAL

RESEARCH NEEDS

III-1

APPENDIX A: FINDINGS OF THE SUBPANEL: EXCHANGE OF INFORMATION BETWEEN GOVERNMENT AGENCIES AND LEADING

NONGOVERNMENT HEALTH PHYSICS AUTHORITIES . . . . . . A A-1

A. Government Agencies

B. The Health Physics Society's Research Needs Committee in Health Physics

C. The Nuclear Regulatory Commission's Health Physics Research Committee

D. The Department of Energy/Pacific Northwest Laboratory's Health Physics Priorities

E. The American National Standards Institute's Standards Committee on Contamination and Release Limits

F. The National Council on Radiation Protection and Measurements

G. The Electric Power Energy Institute and the Nuclear Management and Resources Council

H. The Conference of Radiation Control Program Directors

APPENDIX B: SCIENCE SUBPANEL ON OCCUPATIONAL RADIATION

PROTECTION RESEARCH $\ldots \ldots \ldots \ldots \ldots \ldots \ldots$ B-1 


\title{
RESEARCH PRIORITIES FOR \\ OCCUPATIONAL RADIATION PROTECTION
}

\author{
Executive Summary
}

The Subpanel on Occupational Radiation Protection Research concludes that the most urgently needed research is that leading to the resolution of the potential effects of low-level ionizing radiation. This is the primary driving force in setting appropriate radiation protection standards and in directing the emphasis of radiation protection efforts.

Much has already been done in collecting data that represents a compendium of knowledge that should be fully reviewed and understood. It is imperative that health physics researchers more effectively use that data and apply the findings to enhance understanding of the potential health effects of low-level ionizing radiation and improve the risk estimates upon which current occupational radiation protection procedures and requirements depend. Research must be focused to best serve needs in the immediate years ahead. Only then will we get the most out of what is accomplished.

Beyond the above fundamental need, a number of applied research areas also have been identified as national priority issues. If effective governmental focus is achieved on several of the most important national priority issues, important occupational radiation protection research will be enhanced, more effectively coordinated, and more quickly applied to the work environment. Response in the near term will be enhanced and costs will be reduced by: developing microprocessor-aided "smart" instruments to simplify the use and processing of radiation data; developing more sensitive, energy-independent, and tissue-equivalent dosimeters to more accurately quantify personnel dose; and developing an improved risk assessment technology base. This can lead to savings of millions of dollars in current efforts needed to ensure personnel safety and to meet new, more stringent occupational guidelines. Documentation of workplace radiation levels, personnel external and internal dose, and associated risk assessments is becoming ever more important. Such documentation will ensure that Federal, State, and local agencies are in a more defensible position to avoid billions of dollars of unwarranted litigation costs. Failure to address these needs in a timely manner and to make use of technologies that already have been explored, but not yet applied, will rapidly escalate costs. Additional resources will be required to adequately address public, occupational, and workplace concerns. 
To meet the challenges placed upon occupational radiation protection supervisors and standard setters, the Subpanel concludes that immediate emphasis should be placed on the several key areas noted below.

Development of the best risk estimates for:

- Better understanding of cellular and molecular effects of ionizing radiation

- Experimental data to confirm or modify low dose linear extrapolation theory

- Microdosimetry verification of cell change and damage

Improvements in external dosimetry for:

- High-LET radiation

- Low-LET radiation

- Mixed-field radiation

- Improved experimental measurement data

to verify tissue equivalent dose

Improvements in internal dosimetry for:

- Improved theoretical modeling

- Experimental verification of models

- Uniform systems of application

Improvements in health physics instrumentation for:

- Microprocessor technology

- Improved sensitivity

- Greater versatility and ease of use

- Accreditation and standardization

The Subpanel recommends that the best mechanism for identifying the highest priority research needs and level of funding requirements is to conduct a workshop for each of the major research areas. It is recommended that such workshops be sponsored by the Science Panel of 
the Committee on Interagency Radiation Research and Policy Coordination. Specific occupational radiation protection research projects should be identified and costs should be determined within these workshops and summarized for Science Panel consideration and appropriate emphasis. The Subpanel on Occupational Radiation Protection Research could be of use in evaluating the relative priorities of research needs and providing recommendations to the Science Panel. If effective, each major area emphasized by the Science Panel could be used to justify a priority need. This could help provide the stimulus for agency funding and could greatly assist in bringing high-level agency focus on the importance and urgency of the research requirement.

Participation in these workshops should be open to the health physics research community, including those who have shared their concerns with the Subpanel and with all interested government personnel. This will improve the formulation of needs and assist in the identification of funding requirements. The participation of individuals involved in related disciplines should be actively encouraged to reflect the interdisciplinary nature of the research.

The Subpanel further recommends that it continue to monitor at least on a quarterly basis the progress, shortfalls, and redirection needed and that it continue its interaction with the health physics community. In particular, this should include those who shared so generously in helping to point out the areas of greatest concerns. 


\section{CHAPTER I}

\section{INTRODUCTION}

\section{BACKGROUND}

In a letter, dated October 2,1986, to the Chairman of the Committee on Interagency Radiation Research and Policy Coordination (CIRRPC), Dr. Denwood R. Ross, then Deputy Director of the Office of Nuclear Regulatory Research at the Nuclear Regulatory Commission (NRC), indicated a need for interagency coordination in radiological health protection research and proposed that CIRRPC might be the appropriate organization for coordinating such an effort. The envisioned tasks for a proposed working group were to:

- (a) identify and (b) prioritize the most significant radiological health protection problems that are subject to resolution through research;

- develop interagency strategies for funding and coordinating the higher priority research projects; and

- present the resulting research plans to Administration, Congressional, and Federal agency leaders to assist in obtaining essential support.

It was suggested that only this type of approach would have the highest probability of success for maintaining a focused and adequately funded research program during the years ahead.

At the September 26, 1988 Science Panel meeting, Mr. Thomas Bell of the Department of Energy (DOE) was asked to chair a small ad hoc group to write a work statement for a subpanel to address this issue.

On February 2, 1989, the proposed work statement and suggested role for a Science Subpanel on Occupational Radiation Protection Research was forwarded to Dr. Randall Caswell, the Science Panel Chairman. At the February 6, 1989 Science Panel meeting, the formation of the subpanel was approved, and Mr. Bell was appointed by Dr. Caswell to chair the Subpanel, which held its first meeting on April 14, 1989. 


\section{WORK STATEMENT}

The Subpanel was assigned to review occupational radiation exposure control practices and agency responsibilities for conducting related research; to identify present and anticipated critical needs not addressed currently; and to provide a mechanism for accomplishing established goals on a periodic basis.

The Subpanel was directed to:

1. exchange information on current research programs and describe their expected achievements in terms of worker protection, improvements in dose assessments, and other benefits;

2. identify and describe operational problems of joint Federal interest, the resolution of which can improve the quantity and efficiency of worker protection;

3. examine the results of more basic research programs in instrumentation, dosimetry (including microdosimetry), and radiation related sciences and identify potential applications in the resolution of operational radiation protection problems;

4. describe and prioritize research projects or programs that can be expected to resolve problems identified in 2 above; and

5. prepare reports on findings and conclusions in 1-4 above and provide CIRRPC recommendations that can be used to focus management and budget support for the research required.

\section{OBJECTIVES AND APPROACH}

Objectives

1. Develop a broad-based consensus of the most critical occupational radiation protection research that would facilitate interagency cooperation and funding by obtaining information from noted authorities in the field of health physics. 
2. Develop an interagency mechanism to provide CIRRPC recommendations on:

- issues and research upon which top management and government budget interest can be focused so as to stimulate interagency cooperation and funding for the resolution of practical research needs;

- applied research that would ensure the greatest health benefit for the dollars spent; and

- joint efforts that can prevent duplication of research, with cost savings to the government.

3. Promote and coordinate exchange of information and joint funding, where possible, on:

- current operational radiation protection research needs;

- operational problems that need resolution;

- $\quad$ specific research required to improve present capabilities; and

- projects that have joint Federal agency interest that, if not funded and resolved, will impact the quality and adequacy of future occupational radiation protection.

4. Determine research with operational applications that can capitalize on the already existing fundamental radiation protection research in fields of radiobiology, radiochemistry, microdosimetry, radiation physics, and health physics.

5. Describe and prioritize some critical radiation protection research needs that lend themselves to national focus and interagency funding support and help focus management and budget support to set out on a coordinated effort to solve these identified needs. 
Approach

1. At its first meeting on April 14, 1989, the Subpanel set out to identify those research needs that had the greatest emphasis among the Federal agencies represented on the Subpanel. Most of the agencies currently funding sizeable research efforts were represented.

2. The Subpanel next set out to invite and receive presentations from authorities in different segments of the health physics community. This canvass of occupational radiation protection research needs was considered essential. A broad overview of the country's most pressing research needs is required to better reflect these needs in the Subpanel's recommendations and prioritization.

3. Appendix A of this report summarizes the major inputs of each of these presenters. The Subpanel received presentations from the following personnel:

- Dr. John Auxier, Chairman of the Research Needs Committee, Health Physics Society (May 17, 1989).

- Mr. Leo Faust and Mr. Jack Selby, Co-Chairmen of an independent outside peer committee (Health Physics Research Committee) sponsored by NRC; and DOE representatives to the Pacific Northwest Laboratory - Battelle, as the lead laboratory for recommending DOE health physics-related research (June 14, 1989).

- Mr. George Campbell, Chairman, Health Physics Society Standards Committee for Contamination and Release Limits, and Dr. James Johnson, Recent Advances in HEPA filters; both were from Lawrence Livermore National Laboratory (LLNL) (August 23, 1989). 
- Dr. Warren Sinclair, President of the National Council on Radiation Protection and Measurements (NCRP), who provided NCRP perspectives on current radiation research needs (September 20, 1989).

- Ms. Carol Hornerbrook, Electric Power Research Institute (EPRI), and Ms. Lynne Fairobent, Nuclear Management and Resources Council (NUMARC), who discussed current research needs among the utilities and within the commercial nuclear power community (September 27, 1989).

- Ms. Ruth McBurney, who represented the Conference of Radiation Control Program Directors (CRCPD), which is made up of health physicists representing various State organizations (October 17, 1989).

4. The Subpanel plans to keep communications open with all these groups on a continuing, periodic basis (a review annually or every two years, at the least) to continue the important dialogue established during this initial review in order to continue to reflect diversified community interests and ongoing requirements. 


\section{NATIONAL OCCUPATIONAL RADIATION PROTECTION RESEARCH PRIORITIES}

\section{OVERVIEW}

The Subpanel has found that demands on the operational health physics community are increasing at a rapid rate. This comes at the very time when many of the most noted health physicists are retiring from the profession. The more stringent radiation protection standards that seem to be evolving and the continuing effort to achieve doses "as low as reasonably achievable" (ALARA) are making it ever more important to better understand the health risks associated with low doses of ionizing radiation. It is also driving the need for a whole new generation of radiation monitoring instrumentation and personnel dosimetry that are more sensitive and better able to take into account responses to differing energy levels of radiation. The Subpanel heard from a broad spectrum of the operational health physics community (see Appendix A) and realized that a broad spectrum of issues need attention and must eventually be addressed to ensure that occupational radiation protection programs continue to meet these emerging needs. Radiation research priorities, however, must be organized and focused on those areas that will help most in resolving the most crucial issues. Research priorities must also aim to provide increasingly important improvements to meet more stringent administrative limits and guidelines perceived as necessary to protect the worker and the general public. These important research efforts warrant joint Federal emphasis and funding to ensure their timely resolution.

\section{Basic Problem Areas that Require Nationally Focused Research}

\section{Reduction in the Uncertainties of Risk Assessment}

Because of the importance of the question of acceptability of various risks, and the complex nature of the perceptions of risk, the Subpanel is of the opinion that research in this area is badly needed. Efforts by Federal agencies are already underway in focusing research dollars to reduce uncertainties in risk assessment. This issue has been the primary focus of NRC, DOE, and the Environmental Protection Agency. Their review and progress will be closely followed by other Federal agencies that need to comply with revised risk estimates. 
Uncertainties exist in health risk estimates extrapolated down from high doses. Reducing these uncertainties would provide a firmer basis for individual risk estimates at levels where most of the occupational and environmental exposures occur. Research must be carried out to determine how many people are potentially at risk. Studies that clarify the impacts of dose fractionation on risk coefficients need to be done.

The Health Physics Society has listed risk perception research as one of the top five areas that need major emphasis. They also stress the importance of determining the meaning of "risk" and what is required to provide a balanced perspective of risk.

Federal agencies should work together to find unified ways of educating the public on the magnitude of estimated risks and helping the public put these into perspective. Recent efforts to conduct epidemiology studies can be expanded and, in some cases, jointly funded. Such studies can provide a basis for most informed judgements by the public on the use of nuclear technologies.

\section{Improvements Needed in Personnel Dosimetry}

The development of improved personnel dosimetry is needed to properly document personnel dose. In particular, dosimetry devices must be better able to assess dose equivalent from neutron and beta radiation. Currently, these devices are not adequate. A personnel dosimeter capable of assessing neutron dose equivalent over the entire energy range of neutrons to which an individual might be exposed is needed. Fields of unknown or variable energy distribution in research, industrial, and medical applications complicate this process.

In the case of microdosimetry, concepts for new detection instruments are available for application to radiation protection problems, but they are not being applied. Joint efforts could bring new emphasis and drive to apply and implement these, if enough interest in the radiation protection community can be stimulated and channeled.

The development of Monte Carlo codes in fundamental areas of track structure could be utilized for modeling the distribution of radionuclides in the human body. This effort could assist in developing better estimates of internal dose.

Dosimeters for insertion into phantoms and the human body must be improved, and phantoms that better simulate the human body and improve mock-up capabilities need to be developed. 


\section{Improved Radiation Detection Instrumentation}

The use of microprocessors in radiation-detection instrumentation and the advent of new detector technologies have opened the door to important advances in radiation-detection capability. Joint efforts, if properly orchestrated by Federal, State, and local health physics personnel, could lead to significant new detection capabilities needed to meet the challenges of our advancing technological era. Consistent use and application will increase public confidence in health physics surveys and personnel dose determination to help allay fears generated by the lack of such important data. The following are some examples of new, evolving technologies that lend themselves to joint development and funding:

1. Sensitive/rugged silicon PIN Diode field alpha detectors that greatly improve the capability to monitor personnel and ensure the capability to meet evolving release limits. Instruments that can detect alpha contamination to levels as low as $100 \mathrm{dpm} / 100$ square centimeters are now required. This need taxes current detector technology and drives up the cost of outfitting teams effectively. Improved technology is needed to develop a sensitive, rugged, and durable detector surface that will give the operator a reliable, easily calibrated, and easily repaired instrument.

2. Less expensive, more rugged, and easier to use low-energy gamma/ $\mathrm{x}$ ray detectors to detect Am-241 could greatly enhance the capability to characterize plutonium field contamination. This is needed to improve the speed at which surveys can be taken, to reduce the need for qualified health physicists actually doing field measurements, and to improve response capability.

3. Improved solid state detectors (i.e., SiLi/Ge sandwich) to measure pure Pu-239 in the lung. Whole-body counting is a major component of internal radiation dosimetry. Even with modern state-of-the-art facilities, counting techniques are not sensitive enough to make lung measurements at the regulatory limits of the pure Pu-239. This is due to limitations in the radiation detectors and in the measurements of chest-wall thickness and composition. The transmission of photons is also sensitive to the relative amounts of muscle and fat in the chest wall. Enhanced computer graphics analysis of ultrasonic images is also needed to provide significant improvements in determining the thickness of the chest wall. 
4. Multifunction RADIAC that utilize new state-of-the-art microprocessors in individual smart probes that will increase their ruggedness and sensitivity and permit automated calibration. These changes will greatly reduce the number of redundant instruments, simplify training procedures, reduce the number of spare parts, improve the length of the calibration interval, and save millions of dollars due to greatly reduced calibration and maintenance times.

6. Optically stimulated luminescence technology that would provide an almost universal dosimeter with the capability to measure dose in $\mu$ rad range and could be used for beta, gamma, and neutron monitoring. It would allow the determination of both integrated dose and lifetime dose by using two chips of calcium fluoride.

\section{Internal Dose Assessment}

Good modeling data have come from research projects that had been most heavily funded in the past. There are now relatively good lung and bone models for a few radionuclides. There is still a need, however, for good general metabolic models for a host of radionuclides and tagged compounds. General computer codes for internal dosimetry need to be improved. This includes a better correlation of bioassay data with radionuclide intake. There is also a need for physiological and metabolic data and data on temporal changes within and among organs to improve models and to improve individualized estimates.

Internal dosimetry must be focused to define more clearly the meaning and usefulness of the term "dose" at cellular and subcellular dimensions. The usual relevant unit of exposure, or dose, at the organ or organism level may not be as informative at the cellular level, or at the molecular level where DNA damage and repair occur. The relationship of such microdosimetry to more conventional dosimetry needs clarification. It may be that a greater understanding of the dose distribution in organs and tissues, especially where the radionuclide(s) is not homogeneously distributed, could provide useful information regarding the relative sensitivity of cells or of subcellular or molecular components. 
ASSETS AND MEChanISMS NeEded to EnhanCE RESEARCH EFrortS

In the course of the Subpanel's review of issues and priorities, areas that the Subpanel felt would enhance occupational radiation protection were raised.

\section{Urgent Need for Young Professionals to do Needed Research}

Young career-oriented, scientifically stimulated individuals must be encouraged to join in priority research efforts so they can carry on the work of older health physicists that are leaving the workplace after many years of service. DOE has embarked upon a model program for other Federal and State organizations to emulate and provide similar funding. By financially supporting students toward the completion of their post-graduate degrees in nuclear physics, nuclear engineering, radiation biology, and health physics, new potential Federal and State employees are nurtured. By requiring them to provide service to the parent funding agency prior to completing their doctorate thesis, students provide valuable needed assistance by bringing new and fresh ideas into ongoing programs. Students also benefit from the opportunity to learn about the agencies' needs and requirements in areas they will hopefully become involved and seek employment in after completing their degrees. Fresh perspectives will help in dealing with difficult environmental concerns that can be resolved by pertinent occupational radiation protection research to serve public good and assure safety to individuals in the general population.

\section{Transfer of Fundamental Research to Applied Applications}

Trained personnel must transfer technology from fundamental data to practical applications that help provide current solutions to significant issues in the assurance and assessment of safe occupational radiation protection initiatives. The Subpanel identified several important advances made possible by the transfer of fundamental research to practical applications. These include the development of:

- nanodosimetric and microdosimetric concepts;

- absolute risk-based systems for radiation protection; and

- new and innovative detector concepts. 
Continuing joint efforts on these and similar applications can reap valuable rewards in better utilizing the lifetime work of some of the country's leading scientists.

\section{Enhancement of Accreditation Programs}

There is an important need to standardize and ensure uniform response and dose determination from dosimetry, instrumentation, and bioassay procedures calibrated and tested to uniform and reliable national standards. This also extends to whole-body counting and to internal dose-assessment procedures. Generic guidance is needed on the placement of multiple dosimeters, as well as on the evaluation and calibration of personnel frisking instrumentation. This need is dictated by the ever-increasing litigation processes that call for the documentation and certification of instruments and procedures used to determine external and internal personnel doses. 


\section{CHAPTER III}

\section{CONCLUSIONS AND RECOMMENDATIONS WITH PROJECTED MECHANISMS TO ADDRESS CRITICAL RESEARCH NEEDS}

The Subpanel on Occupational Radiation Protection Research feels that much can be gained by a continuing interface between Federal, State, and health physics professional groups. Research issues should be focused to augment, combine, and expand current efforts, or to make possible new areas of needed research. This is particularly important where it assists in identifying priority research efforts that will result in the ability to better monitor the radiation exposure of personnel and determine more accurately the radiation levels within occupational radiation protection environments. Such efforts should also enhance the agreement and validity of doses determined. This can best be achieved by: a) striving for improvements in accreditation and standardization programs; b) expanding the current understanding of the potential health effects of low-level ionizing radiation; and c) developing the best risk estimates for such exposures.

Trends are dictating the need to more exactly quantify occupational radiation environments and understand the true dose equivalent for individuals. There is no question that agencies are in compliance with current standards. We cannot, however, continue to rely upon current technologies. Changes from current practices to ones driven by increasingly conservative standards will rapidly escalate costs inherent in conducting radiation protection programs and in establishing practices and procedures to comply with these ever-more stringent requirements.

Most dosimetry determinations for individuals are conservatively based. However, uncertainties in dosimetry models and in dose assessments need to be reduced. This will permit a more realistic determination of actual effective dose equivalents. Uncertainties can be reduced by the appropriate research emphasis. Personnel dose assessments are often assigned using the higher end of the uncertainty range. A more accurately determined effective dose equivalent might lower overall calculated collective dose and improve operational costs in occupational radiation protection programs. We must note that such dosimetric improvements often stretch the limits of current technology. This is of particular interest and relevance to the approximately half a million occupational radiation workers who receive some measurable radiation exposure each year. 
The most urgent needs are in the areas of: a) improved external and internal dosimetry data (e.g., measurement, experimental verification, and modeling); b) improved health physics instrumentation that can more effectively verify the growing number of models being developed; and c) the application of the extensive data already collected on the molecular and cellular effects of ionizing radiation, thus making better risk assessment possible.

A consensus is needed to allow focus on the most important occupational radiation research needs within each of these general areas. This is envisioned as an evolving process that will continue to improve as future inputs refine needed goals. It must also deal effectively with discussions of the associated funding necessary to do this critically important research. Input is needed from researchers from all interested Federal agencies and State and nongovernment organizations, as well as from all members of the Science Panel. Such a process will make it possible to clearly see urgent research priorities in their areas. The process must include those with some idea of the funding levels and the time required to see that these are properly developed. This must be done in a manner that makes the most efficient use of available funding (e.g., by jointly funding efforts).

The Subpanel feels that a joint consensus on priority research needs and funding urgencies can best be achieved by organizing a series of workshops for each of the major theme areas noted in the paragraph above and by encouraging meetings on special topics as part of related scientific society meetings. These workshops would be sponsored by the Science Panel of the Committee on Interagency Research and Policy Coordination (CIRRPC). Actions recommended by such workshops could be organized into a three-tiered approach. The first tier would involve actions the Subpanel feels can begin as soon as Science Panel review and concurrence is received. Such actions could be executed easily and without any significant cost. The second tier would involve research initiatives and actions requiring the assistance of, and cooperation between, Federal agencies, with funding that can be identified within ongoing research initiatives. The third tier would involve research efforts related to national priority issues and may only be addressed by focusing attention, emphasis, and the full justification of need and cost impact. These (third tier) important research efforts represent more long-term priority efforts that might best be accomplished in future-year funding with support and assistance from the Office of Science and Technology Policy and/or the Office of Management and Budget. This third tier would rarely be used and would only focus on critical priority issues.

The Subpanel recommends that it continue to fulfill its mission identified in the Work Statement (Chapter 1). 
APPENDIX A: $\quad$ FINDINGS OF THE SUEPANEL: EXCHANGE OF INFORMATION BETWEEN GOVERNMENT AGENCIES AND LEADING

NONGOVERNMENT HEALTH PHYSICS AUTHORTTIES . . . . . . A-1

A. Government Agencies . . . . . . . . . . . . 1

B. The Health Physics Society's Research Needs Committee in Health Physics $\ldots \ldots \ldots \ldots \ldots \ldots \ldots \ldots$

C. The Nuclear Regulatory Commission's Health Physics Research Committee . . . . . . . . . . . . 5

D. The Department of Energy/Pacific Northwest Laboratory's Health Physics Priorities . . . . . . . . . 7

E. The American National Standards Institute's Standards Committee on Contamination and Release Limits . . . . . 8

F. The National Council on Radiation Protection and Measurements ............... 10

G. The Electric Power Research Institute and the Nuclear Management and Resources Council .......... 12

H. The Conference of Radiation Control Program Directors . . 14

APPENDIX B: $\quad$ SCIENCE SUBPANEL ON OCCUPATIONAL RADIATION

PROTECTION RESEARCH $\ldots \ldots \ldots \ldots \ldots \ldots \ldots \ldots$ B-1 


\author{
APPENDIX A \\ FINDINGS OF THE SUBPANEL \\ EXCHANGE OF INFORMATION BETWEEN \\ GOVERNMENT AGENCIES AND LEADING \\ NONGOVERNMENT HEALTH PHYSICS AUTHORITIES
}

\title{
A. Government Agencies
}

\section{Initial Canvass}

\section{Subpanel Consensus}

Each agency conducted an initial survey of radiation protection research issues that were either receiving current priority or that had been identified as possible priority research efforts. The survey resulted in a list of possible priorities, as presented by each Subpanel member.

Initial list/possible priorities (not listed in order of priority):

- Integrated risk and uncertainties of risk estimates

- Health effects of certain frequencies of radiofrequency radiation

- Hot particle skin dose

- Nonradiation hazards

- New science transfer to radiation protection

\ Embryo-fetal dose

- Behavior of respirators

- Health physics instrumentation of the future and their accreditation

$\triangle$ Radioprotectants 
a. NRC provided a comprehensive summary of its radiation protection and health research that served as a model for the later intercomparison of efforts ongoing in other agencies. NRC addresses research in three areas: health effects research, radiation protection issues, and the development of rules and regulatory guides. NRC also emphasized:

- the importance of hot particle skin dose;

- new science transfer to radiation protection;

- suggested interface with the Electric Power Research Institute (EPRI) to better understand the ongoing, approximately $\$ 30$ million radiationrelated research efforts;

- the availability of an important archive of data at the Argonne Center for Human Research on the metabolism and effects of thorium;

- the need for a better model for calculating embryo-fetal dose (currently under development at Pacific Northwest Laboratory);

- the need to address broader research needs beyond just the operational ones;

- NCRP's ongoing literature search to identify research needs; and

A the emphasis needed in health physics instrumentation and the accreditation of survey and fixed counting instruments.

b. Department of Defense (DOD) indicated a shared interest in research related to:

A the development of health physics instrumentation;

$\Delta$ radioprotectants;

$\Delta$ biological indicators of radiation risk; and 
- research that enhances understanding of the health effects of nonionizing, as well as ionizing, radiation.

c. DOE emphasized its research in the area of accreditation for bioassay procedures, which represents a significant research initiative for occupational health and safety.

d. The Center for Devices and Radiological Health of the Food and Drug Administration, Department of Health and Human Services (HHS), indicated interest in research that would benefit its large personnelmonitoring programs.

The Centers for Disease Control of the National Institute of Occupational Safety and Health expressed strong interest in:

- long-term health effects, to women in particular, of radiofrequency sources;

- the evaluation of radiofrequency hazards in industrial settings;

- the need for occupational standards for exposures below $300 \mathrm{~Hz}$; and

$\Delta$ the need for animal research in the $10-30 \mathrm{kHz}$ range.

e. The Department of Labor identified an Occupational Safety and Health Administration need for a better understanding of the behavior of respirators and the physiological and physical impacts of wearing respiratory protection.

\section{B. The Health Physics Society's Committee on Research Needs in Health Physics}

1. Dr. John Auxier, Chairman of the Health Physics Society's (HPS), Committee on Research Needs in Health Physics, provided an informative and helpful briefing on HPS' perspectives of important areas of research needed in the health physics community. He shared with the Subpanel the report Needs for Research 
in Health Physics that was presented to the HPS Board of Directors in June 1988. He also shared a report on Committee Activities (March 16, 1989) and presented a briefing packet that emphasized four general categories of needed health physics research. The general categories currently being considered for emphasis, are:

- waste management;

- radiation exposures, risks, and effects;

- radiation instrumentation technology; and

- models and model validation in health physics.

2. Of particular importance in the last category are the assessment of uptake/excretion in in vivo data (internal dosimetry) and environmental model validation.

3. Of significant note was the perspective that the most effective method for attacking a costly, broad category might be to break each major category, similar to the ones above, into subelements (as shown in the last category above). Some categories many have as many as $\mathbf{2 0}$ or $\mathbf{3 0}$ subelements. Each subelement would be more reasonable to fund and would give Federal agencies the opportunity to collectively share in the accomplishment of the whole category's objective. Dr. Auxier felt that the Subpanel was in an ideal position to share in such collective efforts and to help prioritize those areas needing major emphasis.

4. Great emphasis was placed on improving health physics instrumentation, which is being mandated after a long plateau of satisfaction with current instruments, to comply with new monitoring requirements. It was suggested that a possible way to fund these new requirements, usually mandated by new public laws, would be to have Congress earmark a small share, (perhaps $0.5 \%$ ) of funds appropriated to solve an environmental problem for the development of the instrumentation needed to ensure compliance with that new law.

5. Dr. Auxier emphasized that much has been done in the past to develop a substantial amount of important data, but there needs to be a major emphasis to apply this basic research data to operational health physics. This is particularly significant because many health physicists who developed this data will soon 
retire, and the opportunities for effective application will become more difficult, if not impossible, as the understanding of the data and how to access it is lost.

6. Dr. Auxier pointed out that basic research is shrinking, and we must capitalize on what has already been done in the past. Applied problems are now growing more rapidly than in the recent past, and modern technology needs to be developed to provide solutions.

7. Finally, the needs in the field must be clearly understood to ensure that applied research is timely and effective for the funds expended. Basic research, however, is the basis on which all else is built. These applied research initiatives can save millions if they provide better and cheaper means of achieving goals. Dr. Auxier pointed out that a very important objective of the Subpanel's efforts should be to identify bridges that will permit moving from basic research to solving current occupational health physics problems in the field.

\section{The Nuclear Regulatory Commission's Health Physics Research Committee}

1. Mr. Leo Faust and Mr. Jack Selby, in their capacities as Co-Chairs of the Health Physics Research Committee, sponsored by NRC, presented an overview of health physics research needs identified for NRC. The research needs were the consensus of a distinguished independent, outside peer committee that met in October 1988. The Committee represented a cross-section of DOE national laboratory scientists, reactor power groups, medical physics scientists, and distinguished university members.

2. The NRC-sponsored Committee reviewed and ranked current health physics research, developed a list of proposed new work, and reviewed and ranked the new proposals according to their assessment of the most critical of these research needs. Their efforts were directed toward several important, general areas of concern in radiation protection:

- reducing uncertainty in health risk estimates extrapolated down from high doses (resulting in conservative standards);

- health physics technology improvements to reduce current errors in extremity dosimetry, bioassay, and air sampling; 
- development of consensus performance standards and accreditation programs to ensure high standards of quality assurance;

- required initiatives to ensure implementation of ICRP concepts and Presidential guidance on radiation protection; and

- improvements in waste management technology.

3. The Health Physics Research Committee identified 51 specific issues requiring further health physics research/resolution. Only ten of these were identified as very low priority issues. The five research areas identified as having the highest priority were those that involved:

- guidance necessary for implementing the new 10 CFR 20;

- the development of a basis for balance of risk;

- the determination of how many people are potentially at risk;

- investigation into dose assessment-effective dose equivalent (EDE)nonuniform field exposures; and

- the study of the impact of dose fractionation.

\section{The Department of Energy/Pacific Northwest Laboratory's Health Physics Priorities}

1. Independent of the Health Physics Research Committee's recommendations in section C. above, Mr. Faust and Mr. Selby also presented a review of the key areas where Battelle-Pacific Northwest Laboratory feels important emphasis is needed. Battelle has identified:

a. $\quad$ seven tasks associated with needed neutron research;

b. five tasks in the beta dosimetry area; and

c. eight tasks associated with internal dose assessment that would provide:

- improved computer codes for internal dosimetry;

- better measurement techniques for the assay of plutonium and other transuranics in the lung;

^ improved methods for bone dosimetry; 
- correlation of bioassay data with radionuclide intake; and

- continuous readout internal dosimetry, etc.

2. The five highest priorities identified by Battelle as major DOE research tasks are:

a. the development of combination thermoluminescent/tissue-equivalent dosimeters (TLD/TED);

b. the implementation of effective dose equivalent systems;

c. the development of thin TLD-laser heating technology;

d. the development of a general computer code for internal dosimetry; and

e. the assessment/solutions for impacts of current practices.

3. It was emphasized that the United States is falling behind other countries in developing capabilities necessary to keep track of lifetime dose. The knowledge of lifetime dose is becoming more important in determining which people are actually at risk and in devising procedures to better control higher risk exposure activities. The recent emphasis on radiobiology studies will require a close look at/upgrade of past radiation exposure data to allow its translation into the new effective dose equivalent and committed effective dose equivalent systems called for by Presidential guidance.

4. Other areas requiring support and additional research were also discussed:

a. Much more needs to be done to understand the effects of low-frequency radiation. Although DOE and EPRI place major emphasis ( $\$ 8$ million annually) on low-frequency radiation exposure, particularly in children, additional research is needed.

b. The development of accreditation programs for instrumentation, bioassay systems, and air sampling is needed to ensure that radiation protection programs can detect and properly quantify the effective dose equivalent 
and the committed effective dose equivalent called for by recent changes in guidance.

c. Because the emphasis on risk seems to be rising rapidly, more work is needed to determine the actual dose to specific organs, such as the female breast.

d. Research is needed to ensure that the guidance being developed is made easier to achieve, particularly in the area of internal dosimetry. In some cases this will require the development of a database on which guidance can be effectively based.

5. Mr. Faust called attention to a particularly significant development in the area of neutron-monitoring that would have broad applicability and could merit serious joint efforts to achieve. Optically stimulated luminescence technology, currently being developed, could provide an almost-universal dosimeter. It would have the capability to measure dose in the microrad ( $\mu \mathrm{rad}$ ) range. It could also be used for beta, gamma, and neutron monitoring and would have two chips of calcium fluoride (one permitting the determination of integrated dose and the other permitting the determination of lifetime dose).

\section{E. The American National Standards Institute's Standards Committee on Contamination and Release Limits}

1. As Chairman of the Health Physics Society Standards Committee, Mr. George Campbell reviewed for the Subpanel recent efforts of the American National Standards Institute (ANSI) N-13.12 work on developing relevant surface contamination and release limits. He also provided an overview of important developments in improved isolation techniques for plutonium in the lungs and discussed the need for more effective personnel respirators.

2. Mr. Campbell indicated that:

(DOE) Order 5480.11 requires internal dose monitoring programs to have sufficient sensitivity to be in compliance with radiation protection standards. The annual limit of intake for $\mathrm{Pu}-239$ is $5.5 \mathrm{nCi}$, which results 
in a 50-year effective dose equivalent of $5 \mathrm{rem}$. In addition, DOE has published a draft performance standard that would require workplace monitoring programs to be able to detect intakes that could result in a committed effective dose equivalent of 0.1 rem.

ANSI Standard N-13.30, Performance Criteria for Bioassay, limits the uncertainties for determining $\mathrm{Pu}$ in the lung to $+50 \%$ and $-25 \%$. Even this relatively large range is hard to achieve, because the $17-\mathrm{keV}$ photons from Pu-239 are difficult to detect and are highly absorbed by the chest wall.

3. At present, it is possible to indirectly quantify weapons-grade $\mathrm{Pu}$ by measuring the accompanying Am-241, which emits $60-\mathrm{kV}$ photons. Assuming the plutonium is accompanied by $1200 \mathrm{ppm}$ of $\mathrm{Am}$, measurements of Pu-239 can be inferred. Using a 5-inch phoswich detector, one can infer Pu-239 activities of $3.0 \mathrm{nCi}$. This can be improved by using the $6 \times$ 6-inch phoswich detector, which has a minimum detectable activity (MDA) of $2.3 \mathrm{nCi}$, or by using an intrinsic Germanium (Ge) detector, which has an MDA of $1.1 \mathrm{nCi}$. Mr. Campbell pointed out that it is still not possible to measure pure Pu-239 in the lung at regulatory levels. The most sensitive intrinsic Ge detector has an MDA for pure plutonium in the lung of only $20 \mathrm{nCi}$. This detection level is still about four times above the regulatory limit of $5.5 \mathrm{nCi}$ for $\mathrm{Pu}-239$ in the lung. In addition, measurement is complicated by the chest-wall attenuation of the $17-\mathrm{kV} \times$ rays. Differences in chest-wall thickness can also effect detection capability. For instance, a $40 \%$ fat content in the chest wall can account for a change in detection efficiency by $100 \%$. While these techniques may be adequate for measuring Pu-239 in the chest-wall fat, they are not able to adequately detect Pu-239 in the chest-wall muscle.

4. Mr. Campbell emphasized that there is an important research need to adapt new state-of-the-art detection capability to better detect $\mathrm{Pu}$ in the lung. There is also an important need for improved detectors, as well as for chest-wall and composition measurement techniques. It appears this can best be done by improving $\mathrm{Ge}$ detector technology. It may be possible to use solid-state detectors (i.e., SiLi/Ge sandwich detectors), thus developing a more sensitive array. New high-temperature superconductors and bolometric advances may help to make such advances feasible. It was recommended that Nuclear Magnetic Resonance 
(NMR) also needs to be evaluated as a replacement for ultrasonic techniques to quantify chest-wall composition. Such research initiatives would render great assistance to better detection and quantification of $\mathrm{Pu}$ in the lung. Funding will be needed to select, build, test, and evaluate the appropriate detectors.

5. The ANSI N-13.12 Committee was unable to report on recommended standards on the release of material for uncontrolled levels because the release levels proposed by some were too low to be adequately monitored with current technology. The proposed levels for gamma release limits were proposed at 20 $\mathrm{dpm}$ (swipeable) and $200 \mathrm{dpm}$ (nonswipeable). For beta release, the proposed levels were $500 \mathrm{dpm}$ (swipeable) and $1000 \mathrm{dpm}$ (nonswipeable). Either more sensitive detectors must be developed or decisions must be made on the definition of a reasonably achievable release limit that can be met with current detector technology. It was suggested that this issue might be best resolved by developing a CIRRPC Workshop on what acceptable levels are for uncontrolled release that can be met within current budget constraints. It is becoming apparent that a Committee cannot just sit down and write standards in this area. There is a need for consensus, based on the evaluation of all available data and technology.

6. Mr. Campbell also stressed the need for improvements in personnel respirators. DOL is currently funding research at LLNL to work toward these improvements. The issue of what constitutes an acceptable protection factor and what constitutes acceptable safety in the workplace are the dominant driving factors. It has been difficult to get agreement between National Institute for Occupational Safety and Health (NIOSH) and Occupational Safety and Health Administration (OSHA) on the one hand and ANSI standard setters on the other. ANSI suggests a protection factor of 50 , whereas protection factors of 100 to 500 are currently considered adequate. There are fundamental questions still unanswered in understanding what a respirator is actually doing. Perceptions of respirator performance are changing.

7. Dr. Jim Johnson, LLNL, who gave a presentation with Mr. Campbell, pointed out that additional research is needed on simulated workplace protection factors on elastomeric half masks and disposable respirators. Similar work needs to be carried out on the powered air purifying respirator. The latter shows particular promise. It is a versatile, lightweight, easy-to-use device that merits further careful study. 


\section{F. The National Council on Radiation Protection and Measurements}

1. Dr. Warren Sinclair, NCRP President, stated that much has been done in the past to address a proposed Federal radiation research agenda. This started with the Libassi Report and the work of the Interagency Radiation Research Committee. It was noted that Dr. Caswell, Dr. Gilbert Beebe (HHS) and Dr. William Mills (Oak Ridge Associated Universities), were members of that committee. "The Proceedings of a Public Meeting" on March 10-11, 1980 included a series of issue papers that addressed the following research needs:

- somatic and genetic effects of ionizing radiation;

- limits on extrapolation of the linear hypothesis theory;

- current knowledge from animal and cellular systems;

- significant exposure to internal radiation from environmentally dispersed radionuclides;

- opportunities and limits in applying epidemiological methods;

- information that must be developed to foster enlightened public discussions on the control of man-made ionizing radiation;

- perspectives for public understanding of radiation risk; and

- the legal, ethical, and economic constraints to developing a comprehensive knowledge of the biological effects of ionizing radiation.

Much of these addressed basic research needs, but Dr. Sinclair emphasized that much can be gained from a review of these important issue papers.

2. Dr. Sinclair pointed out that none of these, not even CIRRPC's own report, The Federal lonizing Radiation Research Agenda Related to Low Level Biological Effects: FY 1985 (March 1988), focused on research that could promote occupational health protection. Dr. Sinclair said that the Subpanel's effort to identify occupational radiation protection research that can show impacts in the short term is a noteworthy initiative, and he felt the Subpanel was embarking on a very important endeavor. 
3. Dr. Sinclair stressed that the number one research need, both now and during the NCRP Report 64 study, is the need for continued studies on dose effect relationships and extrapolation dose rate factors. The need for animal research (which has the most problems) and cellular studies on the effects of high LET radiation is also significant. In addition, more research is needed to better understand the fundamental molecular mechanism of mutagenesis.

4. It was pointed out that a major emphasis of NCRP reports in the past, and even more so in recent and evolving reports, is to include a summary or even a chapter that addresses research needs found in the process of preparing the subject report. Dr. Sinclair called attention to several NCRP reports in which this was done and stated that it might be to the Subpanel's benefit to review these as it proceeds. He specifically mentioned: Biological Effects of Ultrasound (Report 74); Radiological Assessment, Model Validation and Simplification (Report 76); Exposures from the Uranium Series, i.e., Radon in Homes (Report 77); The Experimental Basis of Absorbed-Dose Calculations in Medical Uses (Report 83); General Concepts for the Dosimetry of Internally Deposited Radionuclides (Report 84); and Public Radiation Exposure from Nuclear Power Generation (Report 92). Significant emphasis on research needs will also be placed in upcoming NCRP reports $(98,100,101$, and 103$)$.

5. NCRP Committee 83 is currently beginning a major initiative to identify current radiation research needs and will be doing so with a group made up of younger members and designed to encourage input from the younger generation of health physicists. A Senior Panel will oversee the effort, which will also involve the whole NCRP Council in a more general way. In his presentation, Dr. Sinclair said it was unfortunate that the Subpanel could not take advantage of the review as yet, but he anticipated the report's completion by early 1991 . He hoped that the output might be of great benefit to the Subpanel. This review would not address nonionizing radiation but would attempt to prioritize needed radiation research. 


\section{G. The Electric Power Research Institute (EPRI) and the Nuclear Management and Resources Council (NUMARC)}

1. EPRI identified important research needs relative to the commercial nuclear power community. Ms. Pat Robinson (EPRI, Nuclear Power Division) first organized a workshop in 1988 and asked "If you had unlimited resources, what research would you do?" After brainstorming to create a "wish list," a second workshop, with only the utilities, was held to determine how to make this operational. EPRI approved a \$1 million program for FY 1990 to deal with real operational research problems. Funding was being allocated for resolving regulations, worker protection, control costs, and mitigation related to hot particles (a number one priority).

2. A major emphasis was placed on developing a real-time, legal record, effective dose equivalent (EDE) dosimeter to meet growing pressure to limit worker exposure to $1-2 \mathrm{rem} / \mathrm{yr}$.

3. Mechanisms were explored to lower exposure and develop research strategies with the potential to reduce and define capital costs. Seven efforts, in the order of priority, were identified for accomplishment with FY 1990 funds:

a. the development of an effective-dose-equivalent methodology for the assessment of external radiation doses;

b. a radiation characterization database to determine the impact of lower exposure limits;

c. mitigation strategies for discrete radioactive particle generation and exposure;

d. the evaluation of alternatives to contamination protective barriers (improving the critical human factor elements, while maintaining adequate protection against skin contamination);

e. the investigation of international developments in radiation protection guidelines and plant radiation protection practices; 
f. the development of radiation protection operation and maintenance (O\&M) cost reduction strategies (self-monitoring for manpower reduction); and

g. the preparation of dose assignment guidelines.

4. Discrete radioactive particles (DRPs) have a significant impact on commercial nuclear power operations. The activation product Co-60, with its low energy beta, is better understood and less of a problem than "Fuel Fleas, " which are high energy beta ray-emitting particles. In a survey of 61 reactor stations, $21 \%$ of these facilities were found to have no problem from either Co- 60 hot particles or "Fuel Fleas;" $31 \%$ with pressurized reactors experienced problems with "Fuel Fleas;" and $41 \%$ with pressurized reactors experienced problems with Co-60 hot particles. Significant focus is being placed on the prevention of potential acute skin ulcerations (equivalent to small paper cuts). The emphasis to prevent these acute effects is causing: serious heat exhaustion situations; safety concerns by the need to pull individuals out in the middle of an evolution; and work duration times of five minutes or less, which drain the pool of qualified workers very rapidly. More emphasis must be placed on comfort in clothing and the agility in movement so that operations can be done more quickly. Even if relief is provided on Co-60 regulations, there is still the effect of "Fuel Fleas" that is less clearly understood.

5. The Nuclear Management and Resources Council (NUMARC) was created by the Chief Executive Officers of the utilities and the NRC operators. NUMARC was formed to avoid O\&M overlap and effect savings among the Atomic Industrial Forum, EPRI, and the Institute of Nuclear Power Operations. NUMARC is responsible for initiating industry self-improvement efforts when it finds them necessary for public health and safety, as well as for directing attention to, and acting on, regulatory issues NRC considers important. NUMARC also has responsibility for analyzing information concerning generic operational and technical regulatory issues and for identifying those issues that affect, or have the potential to affect, a substantial portion of the nuclear power industry. 


\section{H. The Conference of Radiation Control Program Directors}

1. Ms. Ruth McBurney was designated by the Conference of Radiation Control Program Directors (CRCPD) to act as liaison with the Subpanel on State priorities for occupational radiation protection research. CRCPD is made up of Directors of State and Local Radiation Control organizations and some of their staff. The members of CRCPD's Conference Executive Board reviewed collective State needs and issues and met with Ms. McBurney to report their findings and provide an overview of primary State concerns. Ms. McBurney, on October 16, 1989, shared the results of this canvass with the Subpanel.

2. The Conference Executive Board stressed the need for greater emphasis in the following five general categories, which are listed in the order of priority.

a. radon in homes and work places

- Risk analysis of radon in air and water and verification of water to air transfer factor, including:

o typical particle size;

o equilibrium factors;

0 water limit for ingestion and inhalation; and

0 radon in shower water.

- radon risk-more research and studies that are more definitive on actual health effects and on synergistic effects with other environmental factors.

- dosimetry evaluation and verification.

- methods to verify data and to assure credible results (EPA is helping with some of this).

b. Naturally Occurring and Accelerator-Produced Radioactive Material (NORM/NARM) 
- Primary concern-technically enhanced NORM that is not curently regulated, for example:

0 radium in oil scale removed from pipelines (pipe scale); and

o radium in phosphogypsum, water sludge, cinderblock, and walnut hulls used to filter water.

- Evaluation of health effects.

- Transportation issues-may need new Department of Transportation rules to exempt many of these low-level materials (Possible Below Regulatory Concern [BRC] exemptions)

c. Contamination/disposal limits of NORM/NARM-questions that need to be addressed:

- Should these be regulated like uranium mill tailings?

- Are there disposal alternatives?

- Is there a way to develop consistency among States in addressing this issue?

- What, if any, contamination limits are needed for soil, the decommissioning of facilities, and the land farming of sludge from nuclear laundries?

d. Radiation risks

- Nonionizing radiation health effects, for example:

o radiofrequency radiation around Magnetic Resonance Imaging (MRI) units; and

o radiofrequency radiation around power lines (a highly emotional issue). 
- Health effects of chronic exposure to low-level ionizing radiation.

- Radiation risk in perspective, for example:

o Put the issue into perspective with other risks.

o What exposure levels are considered reasonable?

o What epidemiology studies are needed, country-wide, to address possible related cancer incidence, if any, and related birth defects, if any?

e. Waste management

- Most acceptable methods for the treatment, storage, and disposal of mixed waste.

- Global impact of low-level radioactive waste (overall risk to the public):

- Consider lessons from the United Kingdom and its National Radiological Protection Board, i.e., how they get things done.

- Disposal/use options for diffuse NORM waste. 


\section{APPENDIX B \\ SCIENCE SUBPANEL \\ ON OCCUPATIONAL RADIATION PROTECTION RESEARCH}

Subpanel Members

Department of Energy

Mr. R. Thomas Bell, Chairman

Department of Commerce

Mr. Lester Slaback

Department of Defense

CDR Roby D. Enge, MSC, USN*

Mr. John Manfre

Department of Energy

Mr. John Ahlquist*

Dr. Judith Foulke

Dr. Joel Rabovsky

Dr. Matt Varma

Department of Health and Human Services

Ms. Jeannine T. Lewis*

Department of Labor

Dr. Sheldon R. Weiner

National Aeronautics and Space Administration

Dr. Percival D. McCormack*

Nuclear Regulatory Commission

Mr. Jack Bell*

Ms. Charleen T. Raddatz

Mr. Alan K. Roecklein*

\section{Consultant}

Dr. Tom Crites (Lawrence Livermore National Laboratory)

Technical Program Liaison

Mr. David Smith (ORAU/CIRRPC)

*Original Subpanel Members 